Review

\title{
Telomerase and Cancer: A Complex Relationship
}

Michael Fossel ${ }^{1}$,, Kurt Whittemore ${ }^{2}$

1. Telocyte LLC, Grand Rapids, MI, USA; E-Mail: michael.fossel@telocyte.com

2. Harvard Medical School, Boston, MA, USA; E-Mail: kurtwhittemore@gmail.com

* Correspondence: Michael Fossel; E-Mail: michael.fossel@telocyte.com

Academic Editor: P. Hemachandra Reddy

OBM Geriatrics

2021, volume 5 , issue 1

doi:10.21926/obm.geriatr.2101156
Received: October 26, 2020

Accepted: January 31, 2021

Published: February 03, 2021

\begin{abstract}
Telomere elongation is protective of genomic stability, whereas telomere shortening increases genomic instability and thereby increases cancer risk. Long telomeres lower the risk of clinical cancer, while short telomeres are part of a causal cascade of intracellular events that result in oncogenesis and, ultimately, clinical cancer. Telomerase therapy is not only unlikely to result in an increased risk of cancer but is likely to lower the risk of cancer compared to age-matched patients not treated with telomerase therapy. Review of available data suggests that cancer should not be considered a significant risk to patients undergoing telomerase therapy.
\end{abstract}

\section{Keywords}

Telomerase; telomeres; cancers

\section{Introduction}

Telomerase relengthens telomeres, thereby offering an innovative potential point of therapeutic intervention for age-related human disease $[1,2]$. Given the potential benefits of using telomerase to reset cell senescence and improve human health, and the technical ability to take this approach

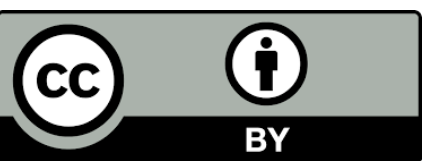

(C) 2021 by the author. This is an open access article distributed under the conditions of the Creative Commons by Attribution License, which permits unrestricted use, distribution, and reproduction in any medium or format, provided the original work is correctly cited. 
to human trials targeting age-related clinical diseases such as Alzheimer's, it is appropriate to assess the possible risks associated with telomerase as a therapy. Among possible risks, the issue of cancer has been raised [3] and will be addressed here.

Potential benefits of telomerase were first described in the medical and lay literature two decades ago [3-5]. At almost the same time, a possible link between telomerase and cancer was also posited and was referred to as the "double-edged sword" of cell senescence [6]. Since that time, supportive data for the therapeutic potential of telomerase has continued to accrue, while discussion has also continued regarding the possible risk of cancer.

The potential benefits of telomerase therapy are based on the observation that age-related diseases are consistent with a model of pathology that includes gradual changes in gene expression, modulated by changes in relative telomere length [7], and culminating in slower molecular turnover, decreased cell maintenance, and a concomitant decrease in DNA repair $[1,8,9]$.

The potential risk of cancer is based on the observation that although cells with sufficiently short telomeres are unable to divide (lowering their risk of malignant growth), many cancers are known to express sufficient telomerase to reenable cell division (while not re-lengthening telomeres sufficiently to upregulate DNA repair [10]). In fact, cancers require telomerase, or more rarely an ALT (alternative lengthening of telomeres) mechanism, to continue to replicate and survive [11, 12].

Evaluation of the risk of cancer in the context of telomere length (and telomerase) is confounded by several problems in the literature. These include three key issues that are rarely appreciated or acknowledged, and which make an assessment of cancer risk prone to error:

\subsection{Inappropriate Cells}

Many studies of telomere length use surrogate tissues or peripheral leukocytes to assess telomere length in cancer, as well as other age-related diseases [13-16], In the case of surrogate tissues, for example, telomeres may be measured in non-cancerous, rather than cancerous cells, rendering the conclusions invalid, as the telomeres in such cells need not represent telomere length (and changes in length) in cancer cells.

The use of peripheral leukocytes (which are easy to sample and widely used) to assess telomere lengths, rather than measuring telomere length in the appropriate cancer cells is questionable. While it is often more difficult to obtain and measure telomeres from cancer cells, and while circulating leukocytes are easily sampled and measured, any conclusions based on this approach are misleading. The telomere lengths of peripheral leukocytes can correlate with those of other tissues [17], but should not be considered accurate indicators, as different tissues undergo different rates of cell aging due to tissue-specific events, for example tissue-specific trauma, infection, or lifestyle choices.

Peripheral leukocytes represent only a small percentage of the body's total leukocytes, and specifically do not represent the underlying telomere lengths of the hematopoietic stem cells resident in the marrow. Leukocytes divide both prior to release from the marrow and after release, in the peripheral circulation (with the primary locus of division differing between $B$ cells, $T$ cells, NKC's, etc.), in response to the needs of the immune system, including infection, stress, and other environmental factors. Telomere lengths in leukocytes are not an accurate reflection of telomere lengths in other, dissociated tissues: the telomeres of a leukocyte have no necessary correlation with the telomeres in hepatic cancer cells, for example. 
Moreover, the telomere lengths of circulating leukocytes vary in dynamic reflection of current physiologic stress, immune status, etc., and they vary widely between leukocyte type as well [18]. In fact, studies finding shorter telomeres in the circulating leukocytes of cancer patients (compared to matched controls) [19-21], may be simply a reiteration of the observation patients with cancer (let alone cancer therapy) are under significant stress and this may be reflected in an increased rate of leukocyte cell division.

In this case, shorter telomeres may be a result, not a cause, of cancer and this is reflected in studies measuring telomere lengths prior to diagnosis, which find no relationship between (future) cancer and leukocyte telomere length [21-25]. The use of peripheral leukocytes to infer telomere lengths in coexisting cancer cells may not be a sufficiently valid or reliable indicator [26], yet all too common in the cancer literature. Such findings offer no useful information regarding the relationship between telomere length and cancer.

\subsection{Inappropriate Measures}

Cell senescence, and especially genomic instability correlate with the shortest telomere length, not with the mean telomere length [27-29]. It is the shortest telomere, whose telomere length signals DNA damage, that sets the pace and determines the cell's ability to divide. Most telomere assays and data reviews [30] reflect the less technically demanding, more available, and cheaper assays for mean telomere length rather than using an assay for the shortest telomere length.

Conclusions based on the use of inappropriate measures are not definitive and may be misleading as to actual physiological events. Cancer cells may have mean telomere lengths that are relatively long, while having several telomeres which are extremely short. The use of mean telomere lengths to infer the relationship between telomere length and cancer is not based on good science and conclusions based on this approach can offer no definitive information.

\subsection{Inappropriate Attribution}

Attribution of causation should not be based on correlation alone. Regardless of this common caveat, some studies, especially those based upon GWAS (genome wide association studies) have suggested that there is a relationship between SNP's (single nucleotide polymorphisms) associated with long telomeres and the risk of cancer [31-36]. Such associations are simply that: associations, without inference as to causation.

A SNP may be responsible for both increased telomere length and increased cancer risk, yet this does not imply that telomere length is causal with regard to cancer. There is no validity to an inference that increased telomere length is responsible for increased cancer risk. The use of correlational data to imply a causal relationship between telomere length and cancer is, a priori, invalid.

Data regarding telomeres, telomerase, and cancer risk often fail to avoid the above errors and should be considered suspect. Nonetheless, the concern regarding cancer remains appropriate and should be carefully addressed, with attention to both theoretical understandings and supportive data, while avoiding the pitfalls listed above. 


\section{Concerns}

The "two-edged sword" theory depicted telomere loss as serving to restrict carcinogenesis at the cost of cell senescence [6]. Essentially, telomeres were portrayed as a zero-sum clinical choice between cancer and aging. In this view, long telomeres served to maintain youthful cell function (avoiding age-related disease) but increased the risk of carcinogenesis. Short telomeres resulted in senescence (resulting in age-related disease) but decreased the risk of carcinogenesis. While this simplistic model has proven an inappropriate and inaccurate representation of reality over the past two decades, there are more complex theoretical models [1], and the data can be difficult to assess, in large part due to misconceptions and errors (as above).

The general context in which telomeres and cancer play a role can be readily sketched. Progression from a normal somatic cell that does not express telomerase to an invasive cancer requires the sequential acquisition of multiple mutations and/or epigenetic alterations and loss-offunction mutations $[37,38]$. In outline, carcinogenesis can be viewed as a cascade of events, with three significant obstacles to progression. The first obstacle to carcinogenesis is DNA damage repair, in which detection and DNA repair pathways replace DNA base errors, thereby halting carcinogenesis. The second obstacle to carcinogenesis is the cell cycle braking system, which detects residual (unrepaired) DNA damage and blocks any further progression of the cell cycle, thereby preventing division and halting carcinogenesis, despite residual DNA errors. The third obstacle to carcinogenesis is cell senescence, in which a sufficiently short telomere stops further cell division, again preventing sustained cell division and halting carcinogenesis. In normal cells, these three steps operate sequentially and effectively, thus routinely terminating cancer risk.

Telomerase, normally present in the germ cell line and to a variable extent in stem cell lines (which are telomerase competent) [39], is not normally present in somatic cells. As a result, lacking telomerase, as somatic cells divide, they progressively lose telomere length and - after sufficient base pairs are lost - enter cell senescence and are no longer capable of cell division. In such cases, the absence of telomerase serves as a "tumor suppressor pathway [40]."

Only cells that 1 ) have residual DNA errors (either through mutation or inherited alleles), 2) have evaded the cell-cycle braking system (usually through mutation or inherited alleles), and 3) have been able to evade terminal cell senescence will be capable of continued cell division, and hence can progress to clinically significant cancer, in which unrestricted cell division and/or metastasis play a role.

Neither theory nor data suggest that telomerase causes cancer. Telomerase is, however, regarded as generally necessary and permissive for continued cell division, a requirement if a cancer cell is to progress from a few, non-clinically-significant cells to a clinically relevant malignancy. In line with this, data show that most (85-90\%) advanced human cancer cells are known to express telomerase [41, 42], but additional factors such as SV40 large T antigen and oncogenic Ras in some cases, are required to obtain a transformed phenotype [41, 42]. If a cancer cell does not express telomerase, or more rarely, utilize an ALT (alternative lengthening of telomeres) mechanism, the cancer would not be able to continue to survive [11]. However, telomerase is not sufficient to cause the cancer. Numerous human cell lines have been immortalized with hTERT, and growth deregulation did not occur [42]. In cancer, telomerase is generally required, but not sufficient.

Although telomeres remain relatively short in many cancer cells, telomerase expression is just sufficient to permit cancer cells to continue to proliferate and avoid reaching senescence [43]. 
Exceptions, cancers that are not telomerase positive, employ alternate mechanisms (not involving telomerase) to maintain just sufficient telomere length to permit continued cell division. Failing this, continued cell division results in progressive shortening of telomeres in cells that do not have a telomere maintenance mechanism, such as telomerase [40].

Telomere maintenance of some kind, whether through telomerase itself or alternative lengthening of telomeres (ALT) $[12,44]$, is necessary for cancer cells to survive, but this does not indicate that telomerase causes cancer. In fact, there are multiple cellular pathways that must become deregulated in a cell to allow for aggressive tumor growth [38], including proliferative signaling, evasion of growth suppressors, activating invasion and metastasis, replicative immortality (through telomere maintenance), induction of angiogenesis, and resistance to cell death.

Despite the presence of telomerase [45] or alternative methods of telomere maintenance, some cancer cells do not have the relatively long telomeres that are typical of young cells. In preneoplasia [46-48], and in most human cancers $[39,49]$, telomeres are relatively short. Such telomeres are just sufficiently long to permit cell division, but markedly shorter than telomeres in young cells with long telomeres and normal DNA maintenance.

In most cancer cells, short telomeres are associated with additional oncogenic alterations and increased chromosome instability $[40,50]$. However, the lengths of telomeres in cancer cells can vary drastically depending on the expression levels of telomerase, replication rates, and nature of the particular cancer [51]. Although cancer cells may have high telomerase expression, their telomeres are far shorter than those of other somatic cells due to their high proliferation rates [52, 53], and long telomeres are predictive of cancer patient survival [54].

Either inherited genetic risk or acquired mutational change can lead to cancer. The former (inherited risk) is associated with increased cancer early in the lifespan, the latter (acquired risk) is associated with increased cancer risk later in the lifespan. In regard to inherited risk, those based upon GWAS (genome wide association studies) frequently find SNP's associated with telomere length [31, 33-36, 55], but, as noted above, there is no indication that long telomeres themselves, as opposed to SNP correlations, increase the risk of cancer [56] (although this has been debated) [57].

Many studies look only at the average rather than the shortest telomere length, further confusing the issue [58-65], and none of the studies analyzing SNP correlations have actually measured telomere lengths, nor have they analyzed telomere lengths in cancer cells. Many of these studies have neglected to measure telomere lengths in the affected tissues, instead using circulating leukocytes (or other, non-cancerous tissues) as their surrogate biomarker [66-68]. Surrogate tissues, and especially leukocytes, are a poor indicator of telomere lengths in cancer tissues. In addition, leukocyte telomere lengths are inherently unreliable due to several factors [26]. In studies looking at actual measured telomere lengths, there is a strong association between short telomeres versus mutation rate and genomic instability [69].

Moreover, there are no published studies showing that lengthening telomeres results in cancer. To the contrary, studies which specifically extend telomere lengths in animals $[70,71]$, generally find no increase in cancer risk. An exception is seen in mice such as the K5-mTert mice which express high levels of telomerase from birth and have higher rates of spontaneous and induced cancer incidence at young ages [72]. However, those K5-mTert mice that do not succumb to cancer at a young age have a mean lifespan $10 \%$ longer than the mean lifespan of mice that lack constitutive 
telomerase expression. Note that mouse cells are also generally more prone to malignant transformation than human cells [73].

\section{Safety: Theory}

Telomerase expression may lower the risk of malignant transformation by stabilizing the genome [1], either via DNA repair or by preventing telomere ends from being recognized as double stranded breaks by DNA repair mechanisms, although the length of telomere (rather than telomerase expression per se) may be the defining factor. A number of studies [74-76] support the consensus that DNA repair declines with age [77]. In a number of diseases, it is telomere lengthening and the prevention of cell senescence that improves chromosome stability $[78,80]$, not vice versa, suggesting that longer telomeres may be essential to chromosomal stability [84].

This was recognized in the early 1990's [78] and was supported experimentally as well: hTERT immortalization confers and is correlated with genetic stability [79] when cells have long (as opposed to short) telomeres [80], whereas telomerase knock-out mice show a striking problem with DNA repair [81]. Instability can be conferred by viral transformation [82] and prior chromosomal damage may increase the risk of malignancy [83], but hTERT-immortalized cells have increased genomic stability $[78,84]$.

This is not to suggest that telomerase per se is protective, only that it may be protective if it lengthens telomeres sufficiently to significantly relengthen telomeres (see figure 1), thereby restoring DNA repair efficacy to levels typical of non-senescent cells. Telomerase promotes genome stability through multiple means. In addition to upregulating DNA repair, it offers increased protection against DNA damage in the nucleus by decreasing mitochondrial ROS production and inhibiting mutations [85]. Down-regulation of DNA-repair, modulated by telomere attrition, explains the common observation that cancer risk rises exponentially with age. Mice have higher cancer rates than humans in a short period of time [73]. The risk of cancer, in both species, increases exponentially with age, as the rates of DNA repair decrease in association with telomere shortening.

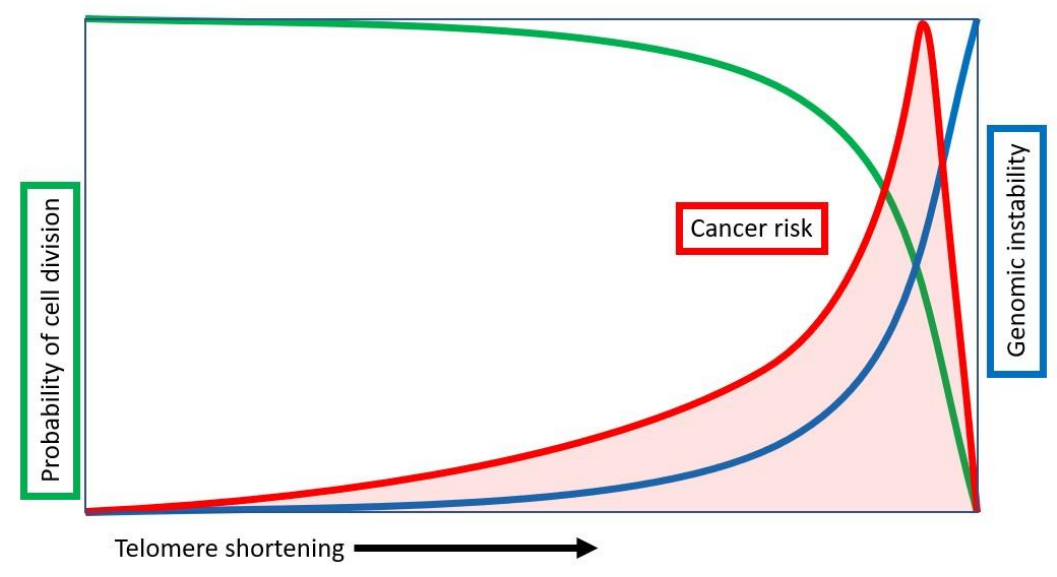

Figure 1 Telomere Length and Cancer Risk. As telomeres shorten, cancer risk maximizes as genomic instability rises and the probability of cell division is not yet at a minimum. Cancer risk then falls as the probability of cell division reaches zero at minimum telomere lengths. Maximum cancer risk occurs with relatively short, but not minimum telomeres, whereas long telomeres and extremely short telomeres are associated with lower cancer risk. 
Telomerase increases genetic stability, thereby lowering the risk of clinical malignancy [86]. This suggests a complex relationship between telomere length and cancer. Cells with long telomeres have a low risk of cancer because of their genomic stability, whereas cells with relatively short telomeres have a high risk of cancer because they are unable to maintain genomic stability [69] but still capable of cell division, while cells with extremely short telomere are incapable of cell division. In general, telomere loss causes genomic instability, with increased risk of both age-related disease and cancer $[14,87,88]$.

The theoretical model, based on the above observations, would suggest a distinct curve for cancer risk versus telomere length (see figure 1) with peak risk found for telomeres at low (but not minimum) lengths or for low levels of telomerase expression, which accords with the clinical data [89-91]. Maximum cancer risk occurs with relatively short telomeres, while lower cancer risk would be associated with long telomeres [92] or with extremely short telomeres.

Cancer cells do require telomerase or ALT to survive. Telomerase knockout mice have been resistant to cancer in several models [93-96]. However, later generations of telomerase knockout mice also have many health problems and short lifespans, indicating the importance of long telomeres and telomerase. Numerous efforts have been made to treat cancer by blocking telomerase [97-99], but these may have harmful effects in the non-cancer cells, resulting in lower proliferative potential as observed in the telomerase knockout mice. Therefore, once cancer is present, if one could selectively inhibit telomerase in the cancer cells only, this may be an effective therapy.

Cells with long telomeres maintain genomic integrity; cells with extremely short telomeres are unable to divide. This has prompted many to suggest that, rather than being regarded as cancer risk, telomerase might actually lower the risk of cancer and, in some cases might offer clinical benefits in cancer therapy as well $[100,101]$. This is certainly in keeping with the growing consensus that telomerase inhibition, rather than being an effective oncology therapy, can result in increasing mutations and metastasis [102]. On the other hand, selectively blocking telomerase in only the cancer cells could be an effective strategy.

Transgenic mice constitutively overexpressing the catalytic subunit of telomerase (mTERT), develop cancers earlier in life (when at highest risk of cancer from inherited gene errors), but this masks the extension of the mean lifespan induced by telomerase in animals that do not develop early cancers [103]. Constitutive telomerase expression in cancer-resistant mice dramatically extended median lifespan by about $40 \%$ and reduced aging-related disorders [104].

In human trials, the intention is to treat human patients late in life and to use transient rather than constitutive expression. In this context, transient telomerase expression would prevent precancerous cells from proliferating continuously, as well as up-regulate DNA repair (thus lowering the risk of DNA damage and secondary cancer), and ameliorate age-related diseases, which are associated with shorter telomere lengths $[105,106]$.

\section{Safety: Data}

Telomerase does not appear to increase the risk of cancer or malignant transformation [87, 107, 108]. Supportive data falls into several groups: 1 ) data showing that short telomeres increase the risk of cancer, 2) data showing that long telomeres decrease the risk of cancer, 3) data showing that 
telomerase activation does not increase cancer risk, and 4) data showing that telomerase expression does not increase cancer risk.

Short telomeres are associated with a greater risk of cancer and patients with short or dysfunctional telomeres have higher rates of cancer [109-113], as well as poorer outcomes [114, 115]. Patients with dyskeratosis congenita (and abnormal telomere maintenance) have an 11-fold increased risk of cancer relative to the normal population, resulting in cancers such as squamous cell carcinomas of the skin, upper aerodigestive and anogenital tract cancers, and hematological malignancies [116], in which long telomeres are a "powerful predictor of survival" [54]. TERT promoter mutations allow a small increase in telomerase expression, but affect only the shortest telomeres, resulting in critically short telomeres, thus permitting continued cell division while promoting genomic instability [117].

Although peripheral leukocytes are an invalid and unreliable biomarker for telomere lengths in other tissues [26], leukocytes with shorter telomeres are more common in patients with cancer [118] and may result in immune dysfunction [119], thereby weakening protection against cancer [119]. Moreover, even normal age-associated cell senescence in the immune system, with its associated decline in immune function, increases cancer risk. The use of telomerase may improve this response and mitigate cancer risk [120].

Short telomeres increase genetic instability and the risk of chromothripsis [121], increasing the risk of cancer. In addition, genetic instability permits cancer cells to adapt and evade chemotherapy. Short telomeres promote metastasis and are correlated with genomic instability and aneuploidy in tumor cells [122]. A review of the link between short telomeres and cancer found extensive evidence that: "telomere attrition is associated with, and probably causative of cancer." With telomere attrition a "recombination between chromosomes occurs, leading to chromosome instability, aneuploidy, and transformation to a cancer phenotype [123]." Cell senescence itself, while initially felt to be a tumor suppressor, is now seen to have paradoxical effects, increasing cancer risk [124].

A metanalysis of 56 papers published between $2015-2017$ found that in $75 \%$ of cases, short telomeres were associated with an increased risk of cancer [125]. A larger metanalysis $(11,255$ cases and 13,101 controls from 21 publications) found that "the presence of shortened telomeres may be a marker for susceptibility to human cancer" [111]. Long telomeres, on the other hand, are associated with a lower risk of cancer [126]. In this respect, telomerase acts as a tumor suppressor, ensuring genomic stability and inhibiting mutations [85].

Interventions which activate telomerase in cells have shown no increase in cancer risk. When human cells are transfected with TERT, for example, there is no evidence of cancer, abnormal growth control, change in karyotype, or phenotype transformation [107, 108, 127, 128]. Likewise, when human cells are transfected with a telomerase gene and then used to reconstitute human tissues, there is no evidence of malignancy [129].

Animal studies show similar findings $[106,130]$. Increasing telomerase expression in adults results in benefits including increased lifespan, without evidence of increased cancer. Likewise, animals generated to have longer telomeres show less DNA damage, fewer tumors, and are healthier $[92,131]$. This has also been seen in mice that have been genetically altered to express telomerase in response to tamoxifen and also in normal mice that have been given a transientlyexpressed telomerase gene. In the former case [132], telomerase reactivation extended telomeres, reduced DNA damage signaling, allowed quiescent cultures to resume proliferation, and eliminated 
degenerative phenotypes in multiple tissues. In the latter case [71], median lifespan was increased by about $24 \%$ when the mice were treated at 1 year of age and the mice were healthier (increased insulin sensitivity, decreased osteoporosis, increased neuromuscular coordination, and improvement of several biomarkers of aging), with no increase in cancer. As mice are generally even more susceptible to cancer than humans [131, 133], this also speaks to the relative risk of telomerase in human trials. So if telomerase expression is safe in mice, it may be safe in humans.

Despite a broad expression of the TERT gene, there was no increase in cancer compared to control mice, suggesting that the gene therapy approach to deliver telomerase to individual cells in tissue is safe. "This study demonstrates that telomerase expression using gene therapy is a viable approach for improving healthspan and extending lifespan without increasing cancer incidence, even in organisms that are much more susceptible to cancer development than humans [106]."

Additionally, telomerase overexpression does not accelerate onset or progression of carcinomas, even in the setting of a p53-null background. Telomerase activation using AAV9-TERT gene therapy has no detectable cancer-prone effects, even in cancer prone mice with oncogene-induced tumors [86].

In human studies, using an orally administered telomerase activator, not only has there been no evidence of an increased risk of cancer [134-135], but there is evidence that the incidence of cancer actually decreases significantly [134]. Parallel results are seen when mice are given the same oral telomerase activator $[137,138]$.

\section{Human Trials}

Human gene therapy trials are planned, employing AAV9, a non-integrating viral vector with transient expression of the hTERT gene (TERT does not integrate into the genome or integrates at a very low frequency [139]). Serial dilution of the hTERT gene, and therefore loss of hTERT gene expression, will occur with each cell division.

A cell that becomes malignant would not have the benefit of increased telomerase expression from telomerase gene therapy, while in non-malignant cells, elongation of the telomere would have already lowered genomic instability, thus lowering the risk of mutation and oncogenesis. Moreover, the viral vector will not replicate in vivo, as replication requires a helper plasmid [71]. Under such circumstances, cells with abnormal growth control and rapid cell division will be the first to lose telomerase expression, a further brake upon potential cancer growth. Cells with normal growth control will have a lower incidence of mutation and malignant transformation.

In light of current data, as well as the known function of viral vector delivery, both theory and available data support the view that telomerase therapy is safe and unlikely to cause cancer in human trials. While it remains possible that telomerase therapy might increase cancer risk in rare individuals ${ }^{*}$, the evidence is against it: telomerase therapy should have the net effect of suppressing cancer in treated humans [134]. Specifically, current data supports the inference that: 1) malignant transformation due to telomerase is unlikely and 2) telomerase therapy is likely to lower the cancer risk in such patients to below that typical of age-matched control groups.

\footnotetext{
* Patients with neither telomerase nor ALT, but with short telomeres and carcinogenic potential, might incur increased risk if telomerase expression both remains constitutive (does not dilute or cease) and does not induce sufficient lengthening of telomeres to induce DNA repair.
} 


\section{Conclusions}

Several points should be stressed in summarizing our current knowledge of the relationship between telomere length, telomerase, genomic stability, and cancer.

1) Does telomerase activity increase the risk of cancer?

No. Malignant transformation requires other mutations or disrupted pathways. Telomerase itself is not sufficient to cause growth deregulation, mutation, or malignant transformation. Once a cell becomes malignant, however, then either telomerase or ALT are necessary for such cells to proliferate and result in clinical cancer.

2) Does telomerase benefit the normal cell?

Yes. Telomerase prevents genomic instability and decreases the risk of transformation from normal to malignant cell. Once such transformation occurs, however, then the absence of telomerase (or the presence of telomerase inhibition) may prevent further cell division and proliferation of the malignant cell.

3) Is the telomerase/cancer relationship simple?

No. Its effects are complex and are dependent upon whether or not a cell has already incurred genetic damage and consequent growth dysregulation. In normal cells, telomerase can prevent mutation by preventing genomic instability and malignant transformation. Once such a transition occurs, however, telomerase activity (or ALT) may permit such proliferation of malignant cells, often culminating in overt clinical cancer.

4) Does telomerase protect genomic stability?

Yes. Telomere shortening, on the other hand, increases genomic instability and thereby increases cancer risk. Long telomeres lower the risk of clinical cancer, while short telomeres are part of a causal cascade of intracellular events that results in oncogenesis and, ultimately, clinical cancer. Telomerase therapy is not only unlikely to result in an increased risk of cancer but is likely to lower the risk of cancer compared to age-matched patients not treated with telomerase therapy.

Review of available data suggests that cancer should not be considered a significant risk to patients undergoing telomerase therapy, but the actual outcome will require human trials.

\section{Author Contributions}

Dr. Fossel wrote the majority of the paper with significant and invaluable input from Dr. Whittemore.

\section{Competing Interests}

The authors have declared that no competing interests exist.

\section{References}

1. Fossel M. Cells, aging, and human disease. 1st ed. Oxford: Oxford University Press; 2004.

2. Fossel $M$. The role of telomerase in age-related degenerative disease and cancer. Adv Cell Aging Gerontol. 2001; 7: 163-204.

3. Banks DA, Fossel M. Telomeres, cancer, and aging: Altering the human lifespan. JAMA. 1997; 278: $1345-1348$. 
4. Fossel M. Telomerase and the aging cell: Implications for human health. JAMA. 1998; 279: 17321735.

5. Fossel M. Reversing human aging. New York: Quill; 1997.

6. Campisi J. Aging and cancer: The double-edged sword of replicative senescence. J Am Geriatr Soc. 1997; 45: 482-488.

7. Robin JD, Ludlow AT, Batten K, Magdinier F, Stadler G, Wagner KR, et al. Telomere position effect: Regulation of gene expression with progressive telomere shortening over long distances. Genes Dev. 2014; 28: 2464-2476.

8. Fossel M. Cell senescence in human aging: A review of the theory. In Vivo. 2000; 14: 29-34.

9. Fossel M. Cell senescence in human aging and disease. Ann N Y Acad Sci. 2002; 959: 14-23.

10. Sharma GG, Gupta A, Wang H, Scherthan H, Dhar S, Gandhi V, et al. hTERT associates with human telomeres and enhances genomic stability and DNA repair. Oncogene. 2003; 22: 131146.

11. Granger MP, Wright WE, Shay JW. Telomerase in cancer and aging. Crit Rev Oncol Hematol. 2002; 41: 29-40.

12. Cesare AJ, Reddel RR. Alternative lengthening of telomeres: Models, mechanisms and implications. Nat Rev Genet. 2010; 11: 319-330.

13. Epel ES, Merkin SS, Cawthon R, Blackburn EH, Adler NE, Pletcher MJ, et al. The rate of leukocyte telomere shortening predicts mortality from cardiovascular disease in elderly men. Aging. 2008; 1: 81-88.

14. Blackburn EH, Epel ES, Lin J. Human telomere biology: A contributory and interactive factor in aging, disease risks, and protection. Science. 2015; 350: 1193-1198.

15. Adler JK, Hanumanthu VS, Strong MA, DeZern AE, Stanley SE, Takemoto CM, et al. Diagnostic utility of telomere length testing in a hospital-based setting. Proc Natl Acad Sci U S A. 2018; 115: E2358-E2365.

16. Alder JK, Chen JL, Lancaster L, Danoff S, Su S, Cogan JD, et al. Short telomeres are a risk factor for idiopathic pulmonary fibrosis. Proc Natl Acad Sci U S A. 2008; 105: 13051-13056.

17. Demanelis K, Jasmine F, Chen LS, Chernoff $M$, Tong L, Delgado D, et al. Determinants of telomere length across human tissues. Science. 2020; 369.

18. Lin J, Epel E, Cheon J, Kroenke C, Sinclair E, Bigos M, et al. Analyses and comparisons of telomerase activity and telomere length in human $\mathrm{T}$ and $\mathrm{B}$ cells: Insights for epidemiology of telomere maintenance. J Immunol Methods. 2010; 352: 71-80.

19. McGrath M, Wong JY, Michaud D, Hunter DJ, De Vivo I. Telomere length, cigarette smoking, and bladder cancer risk in men and women. Cancer Epidemiol Biomarkers Prev. 2007; 16: 815-819.

20. Shen J, Gammon MD, Terry MB, Wang Q, Bradshaw P, Teitelbaum SL, et al. Telomere length, oxidative damage, antioxidants and breast cancer risk. Int J Cancer. 2009; 124: 1637-1643.

21. Pooley KA, Sandhu MS, Tyrer J, Shah M, Driver KE, Luben RN, et al. Telomere length in prospective and retrospective cancer case-control studies. Cancer Res. 2010; 70: 3170-3176.

22. Wentzensen IM, Mirabello L, Pfeiffer RM, Savage SA. The association of telomere length and cancer: A meta-analysis. Cancer Epidemiol Biomarkers Prev. 2011; 20: 1238-1250.

23. De Vivo I, Prescott J, Wong JY, Kraft P, Hankinson SE, Hunter DJ. A prospective study of relative telomere length and postmenopausal breast cancer risk. Cancer Epidemiol Biomarkers Prev. 2009; 18: 1152-1156. 
24. Zee RY, Castonguay AJ, Barton NS, Buring JE. Mean telomere length and risk of incident colorectal carcinoma: A prospective, nested case-control approach. Cancer Epidemiol Biomarkers Prev. 2009; 18: 2280-2282.

25. Weischer M, Nordestgaard BG, Cawthon RM, Freiberg JJ, Tybjaerg-Hansen A, Bojesen SE. Short telomere length, cancer survival, and cancer risk in 47102 individuals. J Natl Cancer Inst. 2013; 105: 459-468.

26. Fossel M. Use of telomere lengths as a biomarker for aging and age-related disease. Curr Tran Geriatr Exp Gerontol Rep. 2012; 1: 121-127.

27. Hemann MT, Strong MA, Hao LY, Greider CW. The shortest telomere, not average telomere length, is critical for cell viability and chromosome stability. Cell. 2001; 107: 67-77.

28. Xu Z, Duc KD, Holcman D, Teixeira MT. The length of the shortest telomere as the major determinant of the onset of replicative senescence. Genetics. 2013; 194: 847-857.

29. Lai TP, Zhang N, Noh J, Mender I, Tedone E, Huang E, Wright WE, Danuser G, Shay JW. A method for measuring the distribution of the shortest telomeres in cells and tissues. Nat Commun. 2017; 8: 1356.

30. Vasko T, Kaifie A, Stope MB, Kraus T, Ziegler P. Telomeres and telomerase in hematopoietic dysfunction: Prognostic implications and pharmacological interventions. Int J Mol Sci. 2017; 18: 2267.

31. Codd V, Mangino M, van der Harst P, Braund PS, Kaiser M, Beveridge AJ, et al. Common variants near TERC are associated with mean telomere length. Nat Genet. 2010; 42: 197-199.

32. Levy D, Neuhausen SL, Hunt SC, Kimura M, Hwang SJ, Chen W, et al. Genome-wide association identifies OBFC1 as a locus involved in human leukocyte telomere biology. Proc Natl Acad Sci USA. 2010; 107: 9293-9298.

33. Prescott J, Kraft P, Chasman DI, Savage SA, Mirabello L, Berndt SI, et al. Genome-wide association study of relative telomere length. PLoS One. 2011; 6: e19635.

34. Mangino M, Hwang SJ Spector TD, Hunt SC Kimura M, Fitzpatrick AL, et al. Genome-wide metaanalysis points to CTC1 and ZNF676 as genes regulating telomere homeostasis in humans. Hum Mol Genet. 2012; 21: 5385-5394.

35. Codd V, Nelson CP, Albrecht E, Mangino M, Deelen J, Buxton JL, et al. Identification of seven loci affecting mean telomere length and their association with disease. Nat Genet. 2013; 45: 422-427.

36. Bojesen SE, Pooley KA, Johnatty SE, Beesley J, Michailidou K, Tyrer JP, et al. Multiple independent variants at the TERT locus are associated with telomere length and risks of breast and ovarian cancer. Nat Genet. 2013; 45: 371-384.

37. Shain AH, Yeh I, Kovalyshyn I, Sriharan A, Talevich E, Gagnon A, et al. The genetic evolution of melanoma from precursor lesions. N Engl J Med. 2015; 373: 1926-1936.

38. Hanahan D, Weinberg RA. Hallmarks of cancer: The next generation. Cell. 2011; 144: 646-674.

39. Shay JW, Wright WE. Telomeres and telomerase in normal and cancer stem cells. FEBS Letters. 2010; 584: 3819-3825.

40. Shay JW. New insights into melanoma development. Science. 2017; 357: 1358-1359.

41. Hahn WC, Counter CM, Lundberg AS, Beijersbergen RL, Brooks MW, Weinberg RA. Creation of human tumour cells with defined genetic elements. Nature. 1999; 400: 464-468.

42. Harley CB. Telomerase is not an oncogene. Oncogene. 2002; 21: 494-502. 
43. Shay JW, Wright WE. Telomerase therapeutics for cancer: Challenges and new directions. Nat Rev Drug Discov. 2006; 5: 577-584.

44. Hu J, Hwang SS, Liesa M, Gan B, Sahin E, Jaskelioff M, et al. Antitelomerase therapy provokes ALT and mitochondrial adaptive mechanisms in cancer. Cell. 2012; 148: 651-663.

45. Popli DB, Sircar K, Chowdhry A. Telomerase: An exploration toward the end of cancer. Indian J Dent Res. 2017; 28: 574-584.

46. Koeneman KS, Pan CX, Jin JK, Pyle JM, Flanigan RC, Shankey TV, et al. Telomerase activity, telomere length, and DNA ploidy in prostatic intraepithelial neoplasia (PIN). J Urol. 1998; 160: 1533-1539.

47. Meeker AK, Gage WR, Hicks JL, Simon I, Coffman JR, Platz EA, et al. Telomere length assessment in human archival tissues: Combined telomere fluorescence in situ hybridization and immunostaining. Am J Pathol. 2002; 160: 1259-1268.

48. Meeker AK, Hicks JL, Platz EA, March GE, Bennett CJ, Delannoy MJ, et al. Telomere shortening is an early somatic DNA alteration in human prostate tumorigenesis. Cancer Res. 2002; 62: 6405-6409.

49. Martinez-Delgado B, Gallardo M, Tanic M, Yanowsky K, Inglada-Perez L, Barroso A, et al. Short telomeres are frequent in hereditary breast tumors and are associated with high tumor grade. Breast Cancer Res Treat. 2013; 141: 231-242.

50. Shay JW, Wright WE. Role of telomeres and telomerase in cancer. Semin Cancer Biol. 2011; 21: 349-353.

51. Haphy CM, Meeker AK. The potential utility of telomere-related markers for cancer diagnosis. J Cell Mol Med. 2011; 15: 1227-1238.

52. Zhan WH, Ma JP, Peng JS, Gao JS, Cai SR, Wang JP, et al. Telomerase activity in gastric cancer and its clinical implications. World J Gastroenterol. 1999; 5: 316-319.

53. Counter CM, Hirte HW, Bacchetti S, Harley CB. Telomerase activity in human ovarian carcinoma. Proc Natl Acad Sci U S A. 1994; 91: 2900-2904.

54. Baljevic M, Dumitriu B, Lee JW, Paietta EM, Wiernik PH, Racevskis J, et al. Telomere length recovery: A strong predictor of overall survival in acute promyelocytic leukemia. Acta Haematol. 2016; 136: 210-218.

55. Levy D, Neuhausen SL, Hunt SC, Kimura M, Hwang SJ, Chen W, et al. Genome-wide association identifies OBFC1 as a locus involved in human leukocyte telomere biology. Proc Natl Acad Sci U S A. 2010; 107: 9293-9298.

56. Pooley KA, Bojesen SE, Weischer M, Nielsen SF, Thompson D, Al Olama AA, et al. A genomewide association scan (GWAS) for mean telomere length within the COGS project: Identified loci show little association with hormone-related cancer risk. Hum Mol Genet. 2013; 22: 50565064.

57. Haycock PC, Burgess S, Nounu A, Zheng J, Okoli GN, Bowden J, et al. Association between telomere length and risk of cancer and non-neoplastic diseases: A mendelian randomization study. JAMA Oncol. 2017; 3: 636-651.

58. Du J, Xue W, Ji Y, Zhu X, Gu Y, Zhu M, et al. U-shaped association between telomere length and esophageal squamous cell carcinoma risk: A case-control study in Chinese population. Front Med. 2015; 9: 478-486.

59. Martins CS, Santana-Lemos BA, Saggioro FP, Neder L, Machado HR, Moreira AC, et al. Telomere length and telomerase expression in pituitary tumors. Endocrinol Invest. 2015; 38: 1243-1246. 
60. Liu C, Li B, Li L, Zhang H, Chen Y, Cui X, et al. Correlations of telomere length, P53 mutation, and chromosomal translocation in soft tissue sarcomas. Int J Clin Exp Pathol. 2015; 8: 5666-5673.

61. Zeng $\mathrm{H}, \mathrm{Wu} \mathrm{HC}$, Wang $\mathrm{Q}$, Yang $\mathrm{HI}$, Chen $\mathrm{CJ}$, Santella RM, et al. Telomere length and risk of hepato-cellular carcinoma: A nested case-control study in Taiwan cancer screening program cohort. Anticancer Res. 2017; 37: 637-644.

62. Naing C, Aung K, Lai PK, Mak JW. Association between telomere length and the risk of colorectal cancer: A meta-analysis of observational studies. BMC Cancer. 2017; 17: 24.

63. Kuzyk A, Gartner J, Mai S. Identification of neuroblastoma subgroups based on threedimensional telomere organization. Transl Oncol. 2016; 9: 348-356.

64. Caini S, Raimondi S, Johansson H, De Giorgi V, Zanna I, Palli D, et al. Telomere length and the risk of cutaneous melanoma and non-melanoma skin cancer: A review of the literature and meta-analysis. Dermatol Sci. 2015; 80: 168-174.

65. Wennerström EC, Risques RA, Prunkard D, Giffen C, Corley DA, Murray LJ, et al. Leukocyte telomere length in relation to the risk of Barrett's esophagus and esophageal adenocarcinoma. Cancer Med. 2016; 5: 2657-2665.

66. Yang M, Prescott J, Poole EM, Rice MS, Kubzansky LD, Idahl A, et al. Prediagnosis leukocyte telomere length and risk of ovarian cancer. Cancer Epidemiol Biomarkers Prev. 2017; 26: 339345.

67. Hou L, Zhang X, Gawron A J, Liu J. Surrogate tissue telomere length and cancer risk: Shorter or longer? Cancer Lett. 2012; 319: 130-135.

68. Ennour-Idrissi K, Têtu B, Maunsell E, Poirier B, Montoni A, Rochette PJ, et al. Association of telomere length with breast cancer prognostic factors. PLoS ONE. 2016; 11: e0161903.

69. Hacket JA, Feldser DM, Greider CW. Telomere dysfunction increases mutation rate and genomic instability. Cell. 2001; 106: 275-286.

70. Jaskelioff M, Muller FL, Paik JH, Thomas E, Jiang S, Adams A, et al. Telomerase reactivation reverses tissue degeneration in aged telomerase deficient mice. Nature. 2011; 469: 102-106.

71. de Jesus BB, Vera E, Schneeberger K, Tejera AM, Ayuso E, Bosch F, et al. Telomerase gene therapy in adult and old mice delays aging and increases longevity without increasing cancer. EMBO Mol Med. 2012; 4: 691-704.

72. González-Suárez E, Geserick C, Flores JM, Blasco MA. Antagonistic effects of telomerase on cancer and aging in K5-mTert transgenic mice. Oncogene. 2005; 24: 2256-2270.

73. Rangarajan A, Weinberg RA. Opinion: Comparative biology of mouse versus human cells: Modelling human cancer in mice. Nat Rev Cancer. 2003;3: 952-959.

74. Higami Y, Shimokawa I, Okimoto T, Ikeda T. Vulnerability to oxygen radicals is more important than impaired repair in hepatocytic deoxyribonucleic acid damage in aging. Lab Invest. 1994; 71: 650-656.

75. Moriwaki S, Ray S, Tarone RE, Kraemer KH, Grossman L. The effect of donor age on the processing of UV damaged DNA by cultured human cells: Reduced DNA repair capacity and increased DNA mutability. Mutat Res. 1996; 364: 117-123.

76. Gilchrest BA, Bohr VA. Aging processes, DNA damage, and repair. FASEB J. 1997; 11: 322-330.

77. Hadshiew IM, Eller MS, Gilchrest BA. Age-associated decreases in human DNA repair capacity: Implications for the skin. Age. 1999; 22: 45-58. 
78. Counter CM, Avilion AA, LeFeuvre CE, Stewart NG, Greider CW, Harley CB, et al. Telomere shortening associated with chromosome instability is arrested in immortal cells which express telomerase activity. EMBO J. 1992; 11:1921-1919.

79. Roque RS, Agarwal N, Wordinger RJ, Brun AM, Xue Y, Huang LC, et al. Human papillomavirus 16 E6/E7 transfected retinal cell line expresses the Muller cell phenotype. Exp Eye Res. 1997; 64: 519-527.

80. Amit M, Carpenter MK, Inokuma MS, Chiu CP, Harris CP, Waknitz MA, et al. Clonally derived human embryonic stem cell lines maintain pluripotency and proliferative potential for prolonged periods of culture. Dev Biol. 2000; 227: 271-278.

81. Wong KK, Chang S, Weiler SR, Ganesan S, Chaudhuri J, Zhu C, et al. Telomere dysfunction impairs DNA repair and enhances sensitivity to ionizing radiation. Nat Genet. 2000; 26: 85-88.

82. Coursen JD, Bennett WP, Gollahon L, Shay JW, Harris CC. Genomic instability and telomerase activity in human bronchial epithelial cells during immortalization by human papillomavirus 16 E6 and E7 genes. Exp Cell Res. 1997; 235: 245-253.

83. Bernal A, Zafon E, Dominguez D, Bertran E, Tusell L. Generation of immortalised but unstable cells after hTERT introduction in telomere-compromised and p53-deficient vHMECs. Int J Mol Sci. 2018; 19: 2078.

84. Golubovskaya VM, Filatov LV, Behe Cl, Presnell SC, Hooth MJ, Smith GJ, et al. Telomere shortening, telomerase expression, and chromosome instability in rat hepatic epithelial stem like cells. Mol Carcinog. 1999; 24: 209-217.

85. Low KC, Tergaonkar V. Telomerase: Central regulator of all of the hallmarks of cancer. Trends Biochem Sci. 2013; 38: 426-434.

86. Munoz-Lorente MA, Martinez P, Tejera A, Whittemore K, Moises-Silva AC, Bosch F, et al. AAV9mediated telomerase activation does not accelerate tumorigenesis in the context of oncogenic K-Ras-induced lung cancer. PLoS Genet. 2018; 14: e1007562.

87. Harley $C B$, Futcher $A B$, Greider $C W$. Telomeres shorten during aging of human fibroblasts. Nature. 1990; 345: 458-460.

88. de Lange T, Lundblad V, Blackburn E. Telomeres, 2nd ed. Cold Spring Harbor : Cold Spring Harbor Laboratory Press; 2006.

89. Yang B, Shebl FM, Sternberg LR, Warner AC, Kleiner DE, Edelman DC, et al. Telomere length and survival of patients with hepatocellular carcinoma in the United States. PLoS One. 2016; 11: e0166828.

90. Shahin M, Saeednejad Zanjani L, Abolhasani M, Rahbar M, Asgari M, Madjd Z. Low level expression of human telomerase reverse transcriptase predicts cancer-related death and progression in embryonal carcinoma. J Cancer Res Clin Oncol. 2020; 146: 2753-2775.

91. Kachuri L, Latifovic L, Liu G, Hung RJ. Systematic review of genetic variation in chromosome $5 p 15.33$ and telomere length as predictive and prognostic biomarkers for lung cancer. Cancer Epidemiol Biomarkers Prev. 2016; 25: 1537-1549.

92. Varela E, Munoz-Lorente MA, Tejera AM, Ortega S, Blasco MA. Generation of mice with longer and better-preserved telomeres in the absence of genetic manipulations. Nat Commun. 2016; 7: 11739.

93. González-Suárez E, Samper E, Flores JM, Blasco MA. Telomerase-deficient mice with short telomeres are resistant to skin tumorigenesis. Nat Genet. 2000; 26:114-117. 
94. Feldser DM, Greider CW. Short telomeres limit tumor progression In Vivo by inducing senescence. Cancer Cell. 2007; 11: 461-469.

95. Rudolph KL, Millard M, BosenbergMW, DePinho RA. Telomere dysfunction and evolution of intestinal carcinoma in mice and humans. Nat Genet. 2001; 28: 155-159.

96. Jaskelioff M, Song W, Xia J, Liu C, Kramer J, Koido S, et al. Telomerase deficiency and telomere dysfunction inhibit mammary tumors induced by polyomavirus middle T oncogene. Oncogene. 2009; 28: 4225-4236.

97. Betori RC, Liu Y, Mishra RK, Cohen SB, Kron SJ, Scheidt KA. Targeted covalent inhibition of telomerase. ACS Chem Biol. 2020; 15: 706-717.

98. Dikmen ZG, Gellert GC, Jackson S, Gryaznov S, Tressler R, Dogan P, et al. In vivo inhibition of lung cancer by GRN163L: A novel human telomerase inhibitor. Cancer Res. 2005; 65: 7866-7873.

99. Ruden M, Puri N. Novel anticancer therapeutics targeting telomerase. Cancer Treat Rev. 2013; 39: 444-456.

100. Fossel $M$. The telomerase revolution: The enzyme that holds the key to human aging and will lead to longer, healthier lives. Dallas: BenBella Books, Inc.; 2017.

101. Bar C, Thum T. Changing direction - from therapeutic telomerase inhibition to activation? Circ Res. 2017; 120: 1393-1395.

102.Andrews W, Cornell J. Telomere lengthening: Curing all disease including aging and cancer. Reno: Sierra Sciences; 2017.

103.González-Suárez E, Samper E, Ramírez A, Flores JM, Martín-Caballero J, Jorcano JL, et al. Increased epidermal tumors and increased skin wound healing in transgenic mice overexpressing the catalytic subunit of telomerase, mTERT, in basal keratinocytes. EMBO J. 2001; 20: 26192630.

104.Tomás-Loba A, Flores I, Fernández-Marcos PJ, Cayuela ML, Maraver A, Tejera A, et al. Telomerase reverse transcriptase delays aging in cancer-resistant mice. Cell. 2008; 135: 609622.

105.Zhu H, Belchere $M$, van der Harst P. Healthy aging and disease: Role for telomere biology. Clin Sci. 2011; 120: 427-440.

106. Boccardi V, Herbig U. Telomerase gene therapy: A novel approach to combat aging. EMBO Mol Med. 2012; 4: 685-687.

107. Morales CP, Holt SE, Ouellette M, Kaur KJ, Yan Y, Wilson KS, et al. Absence of cancer-associated changes in human fibroblasts immortalized with telomerase. Nat Genet. 1999; 21: 115-118.

108.Jiang XR, Jimenez G, Chang E, Frolkis M, Kusler B, Sage M, et al. Telomerase expression in human somatic cells does not induce changes associated with a transformed phenotype. Nat Genet. 1999; 21: 111-114.

109.Broberg K, Björk J, Paulsson K, Höglund M, Albin M. Constitutional short telomeres are strong genetic susceptibility markers for bladder cancer. Carcinogenesis. 2005; 26: 1263-1271.

110.Zhu X, Han W, Xue W, Zou Y, Xie C, Du J, et al. The association between telomere length and cancer risk in population studies. Sci Rep. 2016; 6: 22243.

111. Ma H, Zhou Z, Wei S, Liu Z, Pooley KA, Dunning AM, et al. Shortened telomere length is associated with increased risk of cancer: A meta-analysis. PLoS One. 2011; 6: e20466.

112. Karimi B, Yunesian M, Nabizadeh R, Mehdipour P, Aghaie A. Is leukocyte telomere length related with lung cancer risk: A meta-analysis. Iran Biomed J. 2017; 21: 142-153. 
113.Tu L, Huda N, Grimes BR, Slee RB, Bates AM, Cheng L, et al. Widespread telomere instability in prostatic lesions. Mol Carcinog. 2016; 55: 842-852.

114. Kammori M, Sugishita Y, Okamoto T, Kobayashi M, Yamazaki K, Yamada E, et al. Telomere shortening in breast cancer correlates with the pathological features of tumor progression. Oncol Rep. 2015; 34: 627-632.

115.Lu Y, Yan C, Du J, Ji Y, Gao Y, Zhu X, et al. Genetic variants affecting telomere length are associated with the prognosis of esophageal squamous cell carcinoma in a Chinese population. Mol Carcinog. 2017; 56: 1021-1029.

116.Armanios M, Blackburn EH. The telomere syndromes. Nat Rev Genet. 2012; 13: 693-704.

117. Chiba K, Lorbeer FD, Shain AH, McSwiggen DT, Schruf E, Oh A, et al. Mutation in the promoter of the telomerase gene TERT contribute to tumorigenesis by a two-step mechanism. Science. 2017; 357: 1416-1420.

118. Mons U, Meuzzinler A, Schottker B, Dieffenbach AK, Butterbach K, Schick M, et al. Leukocyte telomere length and all-cause, cardiovascular disease, and cancer mortality: Results from individual-participant-data meta-analysis of 2 large prospective cohort studies. Am J Epidemiol. 2017; 185: 1317-1326.

119. Kaszubowska L. Telomere shortening and ageing of the immune system. J Physiol Pharmacol. 2008; 59: 169-186.

120. Foster AD, Sivarapatna A, Gress RE. The aging immune system and its relationship with cancer. Aging Health. 2011; 7: 707-718.

121. Ernst A, Jones DT, Maass KK, Rode A, Deeg KI, Jebaraj BM, et al. Telomere dysfunction and chromothripsis. Int J Cancer. 2016; 138: 2905-2914.

122. Bojovic B, Crowe DL. Telomere dysfunction promotes metastasis in a TERC null mouse model of head and neck cancer. Mol Cancer Res. 2011; 9: 901-913.

123. Calado RT, Young NS. Telomere diseases. N Engl J Med. 2009; 361: 2353-2365.

124.Kim W, Ludlow AT, Min J, Robin JD, Stadler G, Mender I, et al. Regulation of the human telomerase gene TERT by telomere position effect-over long distances (TPE-OLD): Implications for aging and cancer. PLOS Biol. 2016; 14: e2000016.

125. Andrews B. Novel telomerase therapies, now and in the future [Internet]. Available from: https://www.youtube.com/watch?v=2A2i3Jn63Y.

126. Wan S, Hann HW, Ye Z, Hann RS, Lai Y, Wang C, et al. Prospective and longitudinal evaluations of telomere length of circulating DNA as a risk predictor of hepatocellular carcinoma in HBV patients. Carcinogenesis. 2017; 38: 439-446.

127. Morales CP, Holt SE, Ouellette M, Kaur KJ, Yan Y, Wilson KS, et al. Absence of cancer-associated changes in human fibroblasts immortalized with telomerase. Nat Genet. 1999; 21: 115-118.

128. Bodnar AG, Ouellette M, Frolkis M, Holt SE, Chiu CP, Morin GB, et al. Extension of life-span by introduction of telomerase into normal human cells. Science. 1998; 279: 349-352.

129. Funk WD, Wang CK, Shelton DN, Harley CB, Pagon GD, Hoeffler WK. Telomerase expression restores dermal integrity to in vitro-aged fibroblasts in a reconstituted skin model. Exp Cell Res. 2000; 258: 270-278.

130. Nicholson IP, Gault EA, Foote CG, Nasir L, Bennett D. Human telomerase reverse transcriptase (hTERT) extends the lifespan of canine chondrocytes in vitro without inducing neoplastic transformation. The Veterinary Journal. 2007; 174: 570-576. 
131. Muñoz-Lorente MA, Cano-Martin AC, Blasco MA. Mice with hyper-long telomeres show less metabolic aging and longer lifespans. Nat Commun. 2019; 10: 4723.

132.Jaskelioff M, Muller FL, Paik JH, Thomas E, Jiang S, Adams AC, et al. Telomerase reactivation reverses tissue degeneration in aged telomerase-deficient mice. Nature. 2011; 469: 102-106.

133. Shay JW, Wright WE. When do telomeres matter? Science. 2001; 291: 839-840.

134. Harley CB, Liu W, Flom PL, Raffaele JM. A natural product telomerase activator as part of a health maintenance program: Metabolic and cardiovascular response. Rejuvenation Res. 2013; 16: 386-395.

135. Salvador L, Singaravelu G, Harley CB, Flom P, Suram A, Raffaele JM. A natural product telomerase activator lengthens telomeres in humans: $\mathrm{A}$ randomized, double blind, and placebo controlled study. Rejuvenation Res. 2016; 19: 478-484.

136. Prieto-Oliveira P. Telomerase activation in the treatment of aging or degenerative diseases: A systematic review. Mol Cell Biochem. 2020.

137. de Jesus BB, Schneeberger K, Vera ME, Tejera A, Harley CB, Blasco MA. The telomerase activator TA-65 elongates short telomeres and increases health span of adult old mice without increasing cancer incidence. Aging Cell. 2011; 10: 604-621.

138. Sahin E, DePinho RA. Linking functional decline of telomeres, mitochondria and stem cells during ageing. Nature. 2010; 464: 520-528.

139.Daya S, Berns KI. Gene therapy using adeno-associated virus vectors. Clin Microbiol Rev. 2008; 21: 583-593.

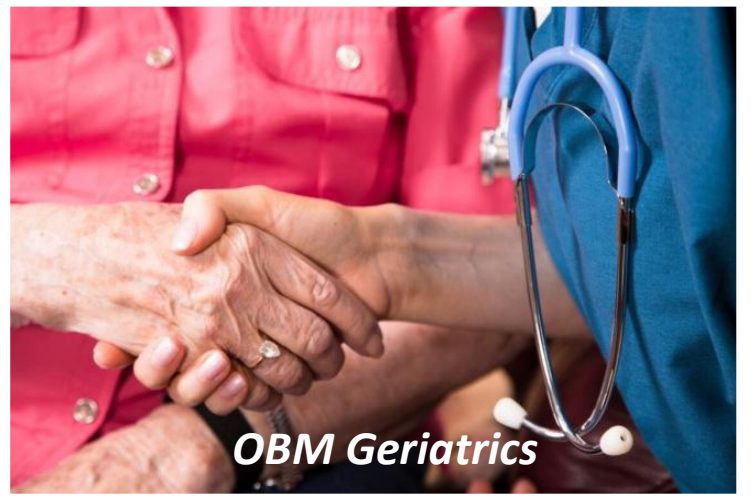

Enjoy OBM Geriatrics by:

1. Submitting a manuscript

2. Joining in volunteer reviewer bank

3. Joining Editorial Board

4. Guest editing a special issue

For more details, please visit: http://www.lidsen.com/journals/geriatrics 